\title{
STRATEGI MARKETING DALAM USAHA MENINGKATKAN VOLUME TRANSAKSI PELANGGAN DENGAN MENGGUNAKAN MOBILE FINTECH APPLICATION OVO
}

\author{
Lusiana Dianingsih \\ Program Studi Magister Manajemen Universitas Tarumanagara \\ lusiana.dianingsih@yahoo.com
}

Masuk : 14-06-2019, revisi : 21-06-2019 diterima untuk diterbitkan : 24-06-2019

\begin{abstract}
This research aims to analyze the impact of product, price/cashback, promotion, and place to increase transaction volume. This research is quantitative by distributing questioner to 100 respondents who are using OVO application. Multiple linier regression is using by using t-test and f-test. The result of this research show that product, price/cashback, promotion, and place have a significant effect to purchase decision, with probability $<0,05$. Variable that have the greatest influence (dominant) of purchase intention is product.
\end{abstract}

Keyword : Fintech, Keputusan Pembelian, Marketing Mix, Strategi Marketing

\begin{abstract}
Abstrak : Penelitian ini dilakukan bertujuan untuk mengetahui bagaimana pengaruh kualitas produk, harga/cashback, promosi, dan tempat terhadap meningkatnya volume transaksi pelanggan. Jenis penelitian ini adalah kuantitatif, dengan pengumpulan data melalui pembagian kuesioner kepada 100 responden yang menggunakan applikasi OVO. Metode analisis yang digunakan adalah regresi liner berganda dengan menggunakan uji t dan uji f. Hasil penelitian menunjukkan bahwa variabel produk, harga/cashback, promosi, tempat terdapat pengaruh yang signifikan terhadap keputusan pemakaian, dibuktikan dengan probabilitas $<0,05$. Variabel yang memiliki pengaruh dominan adalah produk.
\end{abstract}

Keyword : Fintech, Keputusan Pembelian, Marketing Mix, Strategi Marketing

\section{PENDAHULUAN}

Salah satu cara sebuah perusahaan startup untuk memasarkan produk atau brand nya kepada konsumen adalah melalui strategi marketing. pelaksanaan strategi pemasaran yang baik haruslah memperhatikan aspek-aspek yang menjadi sasaran utama dalam melebarkan sayap bisnis perusahaan tersebut. Menciptakan suatu brand baru bukanlah hal yang mudah, oleh sebab itu suatu perusahaan harus memperhatikan aspek-aspek yang menjadi kajian dalam menentukan arah bisnis seperti perlu mengenali adanya product, price, place, promotion, atau yang lebih sering dikenal dengan 4P. Sehingga perusahaan dapat menentukan posisi brand yang diwakilkan dan meningkatkan upaya yang dapat menguntungkan dalam suatu bisnis.

Strategi pemasaran yang dilakukan OVO sebagai startup fintech diharapkan dapat membantu masyarakat Indonesia untuk memilih pembayaran cashless daripada tunai sehingga sesuai dengan ketentuan pemerintah dengan Gerakan Nasional Non Tunai (GNNT).

Tujuan dari penelitian ini adalah untuk mengetahui: (1) pengaruh produk terhadap pengingkatan volume transaksi OVO; (2) pengaruh harga terhadap pengingkatan volume transaksi OVO; (3) pengaruh promosi terhadap pengingkatan volume transaksi OVO; (4) pengaruh lokasi terhadap pengingkatan volume transaksi OVO; (5) variable mana yang paling dominan mempengaruhi pengingkatan volume transaksi OVO. 


\section{TINJAUAN PUSTAKA}

Menurut Kotler (2006:6) marketing adalah sebuah proses kemasyarakatan di mana individu dan kelompok memperoleh apa yang mereka butuhkan dan inginkan dengan menciptakan, menawarkan, dan secara bebas mempertukarkan produk dan jasa yang bernilai dengan orang lain.

Menurut Kotler (2006:48) marketing mix merupakan perangkat pemasaran taktis yang dapat dikendalikan dengan product, price, promote, place atau yang lebih dikenal dengan 4P dimana hal ini yang dapat mengendalikan keuntungan perusahaan. Berikut adalah marketing mix dari sudut pandang perusahaan

Produk, Semua hal yang ditawarkan untuk di konsumsi merupakan suatu produk, baik dalam bentuk barang ataupun jasa. Produk adalah setiap apa saja yang ditawarkan di pasar untuk mendapatkan perhatian, permintaan, pemakaian, atau konsumsi yang dapat memenuhi keinginan atau kebutuhan, Sumarni dan soeprihanto (2010:274).

Menurut Kotler (2006:52) produk dapat dinilai melalui variasi produk, kualitas produk, design, garansi yang ditawarkan, brand, dan karakteristik.

Harga, Menurut Sumarni dan Soeprihanto (2010:281), jumlah uang yang dibutuhkan untuk mendapatkan sejumlah kombinasi dari barang beserta pelayanannya merupakan pengertian dari harga dimana harga produk merupakan elemen yang mampu meningkatkan keuntungan perusahaan.

Promosi, Menurut Tjiptono (2008:219), promosi diartikan sebagai bentuk komunikasi pemasaran, dengan kata lain adalah aktivitas pemasaran yang berusaha menyebarkan informasi, mempengaruhi untuk meningkatkan pasar sasaran atas perusahaan atau produk nya agar bisa diterima, dibeli oleh konsumen dimana biasanya diukur melalui kualitas iklan, sales promotions, kompetitor, public relations.

Tempat, Place dapat diartikan sebagai saluran distribusi yang ada di dalam marketing mix. Sumarni dan Soeprihanto (2010:219) mengartikan saluran distribusi sebagai saluran yang digunakan oleh produsen untuk menyalurkan produk dari produsen sampai ke konsumen atau ke industri pemakai.

Dari beberapa definisi diatas, maka dapat disimpulkan bahwa marketing mix ialah senjata perusahaan untuk memasarkan produknya agar dapat mempengaruhi proses pengambilan keputusan pembelian konsumen

Keputusan Pembelian,Menurut Schiffman dan Kanuk (2000:437), keputusan pembelian merupakan keputusan seseorang dimana seseorang dapat memilih satu dari beberapa alternatif pilihan yang ada sebelum konsumen memutuskan untuk membeli, biasanya konsumen melakukan beberapa tahap analisa terlebih dahulu yaitu, (1) pengenalan masalah, (2) pencarian informasi, (3) evaluasi alternatif, (4) keputusan membeli atau tidak, (5) perilaku pasca pembelian.

\section{Kerangka Penelitian}

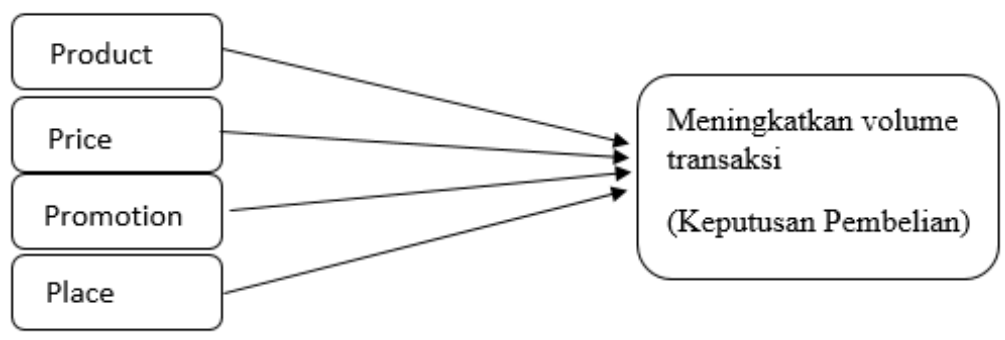

Gambar 1 : Kerangka Penelitian

Sehingga hipotesis dalam penelitian ini adalah sebagai berikut :

H1 : Terdapat pengaruh positif produk terhadap keputusan pembelian dalam usaha meningkatkan volume transaksi konsumen 
H2 : Terdapat pengaruh positif Price/cashback terhadap keputusan pembelian dalam usaha meningkatkan volume transaksi konsumen.

H3 : Terdapat pengaruh positif promosi terhadap keputusan pembelian dalam usaha meningkatkan volume transaksi konsumen.

H4 : Terdapat pengaruh positif place atau lokasi terhadap keputusan pembelian dalam usaha meningkatkan volume transaksi konsumen.

H5 : Variabel produk yang paling dominan mempengaruhi keputusan pembelian dalam usaha meningkatkan volume transaksi konsumen.

\section{METODE PENELITIAN}

Populasi dan Metode Pengambilan Sampel. Jenis penelitian adalah kuantitatif deskriptif dan sumber data diperoleh dari data primer yaitu penyebaran kuisioner dan data sekunder yaitu data kepustakaan. Metode yang digunakan adalah metode survey dengan menggunakan alat bantu kuisioner yang akan dibagikan secara acak kepada 100 responden yang memakai applikasi OVO dalam bertransaksi. Berdasarkan data yang terkumpul, mayoritas karakteristik responden dalam penelitian ini adalah, wanita $(54 \%)$, pegawai swasta $(72 \%)$, dan usia $21-30$ tahun $(71 \%)$. Penelitian ini akan mengungkapkan pengaruh dari strategi marketing terhadap naik atau turun nya volume transaksi yang dikaitkan dengan keputusan pembelian.

Variabel dan Pengukuran. Pada Penelitian ini variabel product, price, place, promotion merupakan variabel independent, sedangkan meningkatnya volume transaksi sebagai variabel dependen. Pengukuran variabel ini menggunakan skala Likert 5 poin dengan 1 merupakan "sangat tidak setuju" dan 5 merupakan "sangat setuju". Dari hasil uji validitas dan reliabilitas menunjukkan bahwa semua variabel yang digunakan adalah valid dan reiliabel.

Metode Analisis Data. Metode analisis data yang digunakan adalah analisis regresi ganda. Sedangkan untuk uji asumsi seperti uji normalitas, uji multikolinearitas dan uji heterkodastisitas telah dilakukan sebelumnya dan hasilnya menunjukkan semua uji asumsi sudah terpenuhi. Pengujian untuk analisis data dilakukan dengan pembagian menjadi 5 model yaitu model 1 untuk menguji hipotesis pertama yaitu pengaruh produk, terhadap keputusan pembelian, model 2 untuk menguji hipotesis kedua yaitu pengaruh price/cashback terhadap keputusan pembelian, model 3 untuk menguji hipotesis ketiga yaitu pengaruh promosi terhadap keputusan pembelian dan model 4 digunakan untuk menguji hipotesis keempat yaitu pengaruh place/lokasi terhadap keputusan pembelian, model 5 digunakan untuk menguji hipotesis kelima yaitu untuk menentukan variabel yang dominan mempengaruhi keputusan pembelian.

\section{ANALISA DAN PEMBAHASAN}

Uji F. Uji F dilakukan untuk mengetahui apakah semua variabel dependen yang dimasukkan mempunyai pengaruh secara bersama-sama terhadap variabel dependen. Dengan menggunakan angka probabilitas $>0.05$ maka $\mathrm{H}_{0}$ ditolak dan $<0.05$ maka $\mathrm{H}_{0}$ diterima.

Tabel 1: Hasil Uji F

\begin{tabular}{|l|l|l|l|l|l|}
\hline Model & $\begin{array}{l}\text { Sum of } \\
\text { Squares }\end{array}$ & df & Mean Square & F & Sig. \\
\hline Regression & 1314,440 & 4 & 328,610 & 117,129 &, $000^{b}$ \\
Residual & 547,080 & 195 & 2,806 & & \\
Total & 1861,520 & 199 & & & \\
\hline
\end{tabular}


Uji t. Untuk mengetahui signifikan atau tidak pengaruh variabel bebas terhadap variabel terikat maka digunakan probability sebesar 5\% $(\alpha=0,05)$. Dengan menggunakan angka probabilitas $>0.05$ maka $\mathrm{H}_{0}$ ditolak dan $<0.05$ maka $\mathrm{H}_{0}$ diterima.

Tabel 2: Uji t

\begin{tabular}{|c|c|c|c|c|c|c|}
\hline \multirow{2}{*}{\multicolumn{2}{|c|}{ Model }} & \multicolumn{2}{|c|}{$\begin{array}{l}\text { Unstandardized } \\
\text { Coefficients }\end{array}$} & \multirow{2}{*}{$\begin{array}{l}\text { Standardized } \\
\text { Coefficients } \\
\text { Beta }\end{array}$} & \multirow[t]{2}{*}{$\mathrm{t}$} & \multirow[t]{2}{*}{ Sig. } \\
\hline & & $B$ & \begin{tabular}{|l|} 
Std. \\
Error
\end{tabular} & & & \\
\hline \multirow{5}{*}{1} & (Constant) & $-2,068$ & ,643 & & $-3,216$ &, 002 \\
\hline & Product & ,453 & 069 & ,368 & 6,530 &, 000 \\
\hline & Harga & , 154 &, 056 & , 145 & 2,742 &, 007 \\
\hline & Promosi & 200 & ,052 & 188 & 3,835 &, 000 \\
\hline & Place & ,326 &, 064 & ,304 & 5,069 &, 000 \\
\hline
\end{tabular}

Koefisien Determinan (R2). Koefisien Determinan digunakan untuk mengetahui besar variabel dependen dijelaskan oleh variabel independen. Nilai koefisien determinasi yang digunakan adalah $0<\mathrm{R}^{2}<1$. Jika (R2) yang diperoleh mendekati 1 (satu) maka dapat dikatakan semakin kuat model tersebut menerangkan hubungan variabel bebas terhadap variabel terikat. Sebaliknya jika (R2) makin mendekati 0 (nol) maka semakin lemah pengaruh variabel-variabel bebas terhadap variabel terikat.

Tabel 3 : Koefisien Regresi

\begin{tabular}{|l|l|l|l|l|}
\hline Model & $\mathrm{R}$ & $\mathrm{R}$ Square & Adjusted R Square & Std. Error of the Estimate \\
\hline 1 &, $840^{\mathrm{a}}$ &, 706 &, 700 & 1,675 \\
\hline
\end{tabular}

Berdasarkan hasil pengujian hipotesis pada model 1, maka dapat disimpulkan bahwa produk berpengaruh secara signifikan terhadap keputusan pembelian. Hipotesis ini sesuai dengan penelitian Baruna, Shilvana dan Hapzi (2017) yang menyatakan bahwa produk akan berpengaruh secara positif terhadap keputusan pembelian ketika kualitas produk dianggap lebih baik dari yang lain.

Hipotesis kedua (model 2) digunakan untuk menguji apakah price/cashback berpengaruh positif terhadap keputusan pembelian. Dan berdasarkan hasil pengujian, diketahui hipotesis terbukti bahwa price/cashback berpengaruh positif terhadap keputusan pembelian. Hal ini sesuai dengan Laela, Andriani dan Kholid (2015) yang menyatakan bahwa price memberikan pengaruh positif terhadap keputusan pembelian dimana price bisa menuntuk customer dalam menciptakan kepuasan konsumen.

Hipotesis ketiga (model 3) untuk menguji apakah promosi berpengaruh positif terhadap keputusan pembelian. Hasil pengujian hipotesis menyatakan bahwa terbukti promosi berpengaruh positif terhadap keputusan pembelian. Hal ini sesuai dengan Wilson dan Sugiono (2014) bahwa promosi berpengaruh terhadap keputusan pembelian, yang artinya semakin baik promosi, maka keputusan pembelian juga akan meningkat secara nyata.

Hipotesis ke empat (model 4) digunakan untuk menguji apakah lokasi berpengaruh positif terhadap keputusan pembelian. Hasil pengujian hipotesis menyatakan bahwa terbukti lokasi mempengaruhi keputusan pembelian. Hal ini sesuai dengan Baruna, Shilvana dan Hapzi (2017) yang menyatakan lokasi merupakan strategi yang dilakukan agar produk dapat mudah digunakan. 
Hipotesis kelima (model 5) untuk menguji diantara produk, harga, promosi, lokasi, mana yang lebih dominan mempengaruhi keputusan pembelian. Hasil pengujian menyatakan bahwa produk merupakan yang paling dominan mempengaruhi keputusan pembelian, hal ini sesuai dengan Wilson dan Sugiono (2014).

Berdasarkan kesimpulan diatas, maka seluruh hipotesis penelitian ini terbukti dengan adanya data empiris. Dengan demikian maka dapat dilihat bahwa produk, promosi, harga, lokasi mempengaruhi secara positif keputusan pembelian dan produk merupakan pengaruh yang paling dominan diantara item yang lain.

\section{PENUTUP}

Kesimpulan. Dalam penelitian ini, menemukan bahwa baik produk, harga, promosi, dan lokasi mempengaruhi keputusan pembelian dan produk merupakan variabel yang berpengaruh secara dominan. Namun bukan hanya produk, harga, promosi dan lokasi saja yang harus diperhatikan pelaku bisnis, tapi juga diperlukan inovasi dan kekuatan brand untuk menghadapi pesaing-pesaing yang bermunculan. Sehingga apabila pelanggan menemukan persepsi yang lebih tinggi di brand lain, dengan sangat mudah pelanggan dapat berpindah. Maka semakin baik kualitas yang diciptakan suatu brand, semakin loyal pula pelanggan. Brand juga perlu memperhatikan dan meningkatkan inovasi untuk tetap menjaga tingkat kepuasan pelanggan terhadap brand sehingga mampu memberikan sesuai harapan pelanggan terhadap produknya.

Saran. Dari kesimpulan diatas, maka penulis memberikan saran agar OVO memperhatikan variabel Product, price, promotion, place dalam kegiatan operasional nya. Hal ini karena ke empat variabel tersebut sudah teridentifikasi berpengaruh terhadap meningkatnya volume transaksi dalam menggunakan mobile application OVO.

\section{DAFTAR PUSTAKA}

Aaker, David. A. (1996). Managing Brand Equity, Capitalyzing on the Value of a Brand Name. New York : The Press.

Alma, Buchari. (2005). Manajemen Pemasaran dan Pemasaran Jasa. Bandung : CV.Alfabeta. Aritonang, R.Lerbin. (2007). Teori dan Praktik Riset Pemasaran. Bogor : Ghalia Indonesia Trump, Donald. (2007). Think Big and Kick Ass in Business and Life. Jakarta : Gramedia Pustaka Utama

Ferrel, O.C, \& D, Harline. (2005). Marketing Strategy. South Western : Thomson Corporation. Freddy, Rangkuti. (2006). Teknik Mengukur dan Strategi Meningkatkan Kepuasan Pelanggan Jakarta : PT Gramedia Pustaka Utama.

Hasan, Ali. (2013). Marketing Dan Kasus-Kasus Pilihan. Yogyakarta : Caps

Engel, James F., (2003) Perilaku Konsumen. Jakarta : Binarupa Aksara.

Jogiyanto. HM. (2005). Metodologi Penelitian Sistem Informasi. Yogyakarta : Andi

Kotler, Philip (2006). Prinsip - prinsip Pemasaran Manajemen. Jakarta : Prenhalindo

Kotler, Philip \& Armstrong, Gary. (2008). Prinsip-prinsip Pemasaran. Jakarta : Erlangga.

Margono. (2004). Metodologi Penelitian Pendidikan. Jakarta : Rineka Cipta.

Marguiles, W.P., (1977). Make the Most of Your Corporate Identity. New York : Harvard Business Review

Schiffman \& Kanuk, (2007).Perilaku Konsumen. Jakarta : PT. Indeks Gramedia

Sugiyono. (2012). Metode Penelitian Kuantitatif Kualitatif dan R\&D. Bandung : CV.Alfabeta

Sumarni, Murti \& Soeprihanto, John. (2010). Pengantar Bisnis (Dasar-dasar Ekonomi Perusahaan). Yogyakarta : Liberty Yogyakarta

Sunyoto, Danang. (2012). Manajemen Sumber Daya Manusia. Jakarta : PT Buku Seru.

Swastha, Basu dan Irawan. (2003). Manajemen Pemasaran Modern. Surabaya : Liberty

Suryani. (2008). Perilaku Konsumen Implikasi Pada Strategi Pemasaran, Yogyakarta: Graha Ilmu

Tjiptono, Fandy. (2012). Strategi Pemasaran. Yogjakarta : Penerbit Andi 